\title{
Dual effects from in-situ polymerized gel electrolyte and boric acid for ultra-long cycle-life Li metal batteries
}

\author{
Yu Han, Ying Zhou, Jie Zhu, Zhenhe Sun, Lingqun Xu, Chenxi Li, Yanfeng Ma, \\ Hongtao Zhang ${ }^{*}$ and Yongsheng Chen
}

Li metal batteries (LMBs) show great potential in energy storage because of their high energy density, but their practical application is hindered by safety issues and poor cycle life due to the growth of Li dendrites $[1,2]$. Although liquid electrolytes (LEs) have remarkable advantages such as high ionic conductivity and good permeability [3], the use of LEs has brought risks of leakage and inevitable lithium dendrite growth. Thus, the inherent safety issues and inferior cycle performance have severely restrained the practical applications of LMBs [4-6]. To address these issues, both inorganic and polymer solid-state electrolytes have been widely explored [7-9]. Whereas, the brittleness and interface contact issues of inorganic solid electrolytes and the low ionic conductivity at room temperature of polymer solid electrolytes greatly blocked their applications [10].

Gel polymer electrolytes (GPEs) could essentially combine the advantages of both solid electrolytes and LEs, such as satisfactory ionic conductivity $\left(10^{-3}-10^{-2}\right.$ $\mathrm{S} \mathrm{cm}^{-1}$ ), good compatibility with electrodes, and reliable safety [11-13]. In recent years, extensive studies have been done to apply GPEs in LMBs, showing significant progress [9]. Unfortunately, the poor cycle life due to the growth of Li dendrites are still the persistent obstacle to their practical application $[14,15]$. Therefore, a gel electrolyte, combining both the advantages of liquid and solid electrolytes, such as high ionic conductivity, good interface contact with electrodes as well as the function of suppressing Li dendrite growth, is still highly desired to meet the requirement for the practical use of LMBs [10].

In this study, with in-situ polymerization and the $n$ butylboronic acid (BBA) as a stable solid electrolyte interface (SEI)-forming additive, we have successfully pre- pared a novel GPE (B-GPE) possessing amounts of advantages including favorable electrolyte/electrode interface, improved stability of lithium hexafluorophosphate $\left(\mathrm{LiPF}_{6}\right)$, the formation of a stable SEI film on the lithium metal surface and the inhibited growth of $\mathrm{Li}$ dendrites. As a result, the battery based on the B-GPE shows an excellent cycling performance with capacity retention of $87.7 \%$ even after 950 cycles at $0.5 \mathrm{C}$.

The B-GPE was obtained by in-situ polymerization of triethylene glycol diacrylate (TEGDA, $0.23 \mathrm{~mol} \mathrm{~L}^{-1}$ ) thermally initiated with azodihetonitrile (ABVN, $0.01 \mathrm{~mol} \mathrm{~L}^{-1}$ ) in an ordinary $\mathrm{LE}$, which had $1 \mathrm{~mol} \mathrm{~L}^{-1}$ $\mathrm{LiPF}_{6}$ salt in a non-aqueous mixture of ethylene carbonate (EC)/dimethyl carbonate (DMC)/diethyl carbonate (DEC) (1:1:1 by volume). Before gelation, a small amount of BBA $\left(0.02 \mathrm{~mol} \mathrm{~L}^{-1}\right)$ was also added to the precursor solution, aimed at forming a boron-based SEI film on the $\mathrm{Li}$ anode surface [16]. The polymerization reaction of TEGDA can proceed at room temperature and form gel after $4 \mathrm{~h}$ [17]. The ether chains of TEGDA could strongly interact with lithium ions and electrolyte solvents [11]. In addition, this polymerization could occur in traditional LEs, indicating its possible wide applicability. Moreover, in-situ polymerization in batteries has been proved as an effective and facile method to prepare GPEs, improving interface contact and reducing interface impedance for ionic transport [18-20]. Besides, the BBA additive can improve the cycling performance by inhibiting lithium dendrite growth. Thus, this gel electrolyte B-GPE exhibits not only favorable electrolyte/electrode interface but also the ultra-long cycle life when used in LMBs (Fig. 1). For comparison, the common gel electrolyte (GPE) without the additive BBA was also prepared in the same way.

The Centre of Nanoscale Science and Technology, Key Laboratory of Functional Polymer Materials, Nankai University, Tianjin 300071, China

* Corresponding authors (emails: yschen99@nankai.edu.cn (Chen Y); htzhang@nankai.edu.cn (Zhang H)) 


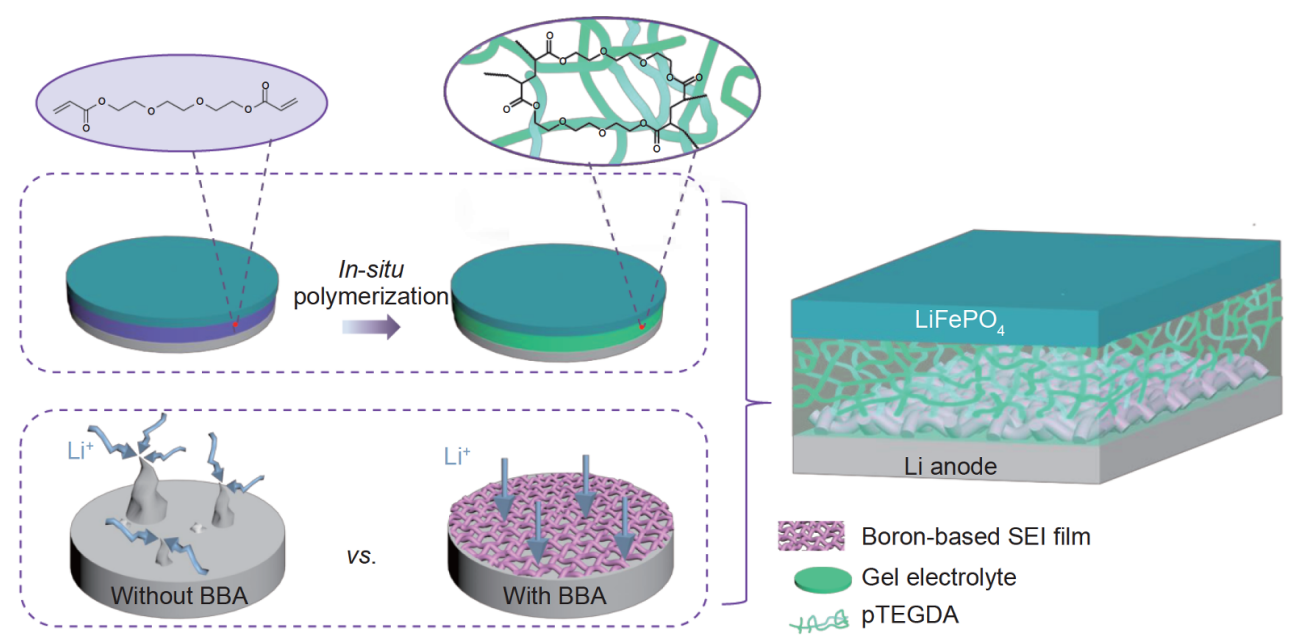

Figure 1 Schematic illustration for the assembling procedure and microscopic model of Li metal battery based on B-GPE.

To confirm the polymerization mechanism, polymer in B-GPE (pTEGDA) extracted from the in-situ polymerized mixture, was analyzed by the Fourier transform infrared spectroscopy (FTIR) (Fig. S1). The peak at about $1633 \mathrm{~cm}^{-1}$ in the spectrum of TEGDA monomer assigned to the stretching vibration of $\mathrm{C}=\mathrm{C}$ bonds, disappears in the spectrum of the polymer matrix. Also, the corresponding $\mathrm{C}=\mathrm{O}$ peak at $\sim 1720 \mathrm{~cm}^{-1}$ moves to $\sim 1770 \mathrm{~cm}^{-1}$ after polymerization. These results indicate that the
TEGDA monomers have been in situ polymerized in the LE successfully (Fig. 2a), leading to the formation of the self-standing gel electrolyte [11].

It has been reported that the use of boron moieties could improve the electrochemical window of electrolytes [21,22]. In Fig. 2b, linear sweep voltammetry (LSV) indicates that the electrochemical window of B-GPE with a small amount of additive has been extended to $4.15 \mathrm{~V}$ versus $\mathrm{Li}^{+} / \mathrm{Li}$ from the value of $4.03 \mathrm{~V}$ versus $\mathrm{Li}^{+} / \mathrm{Li}$ for the
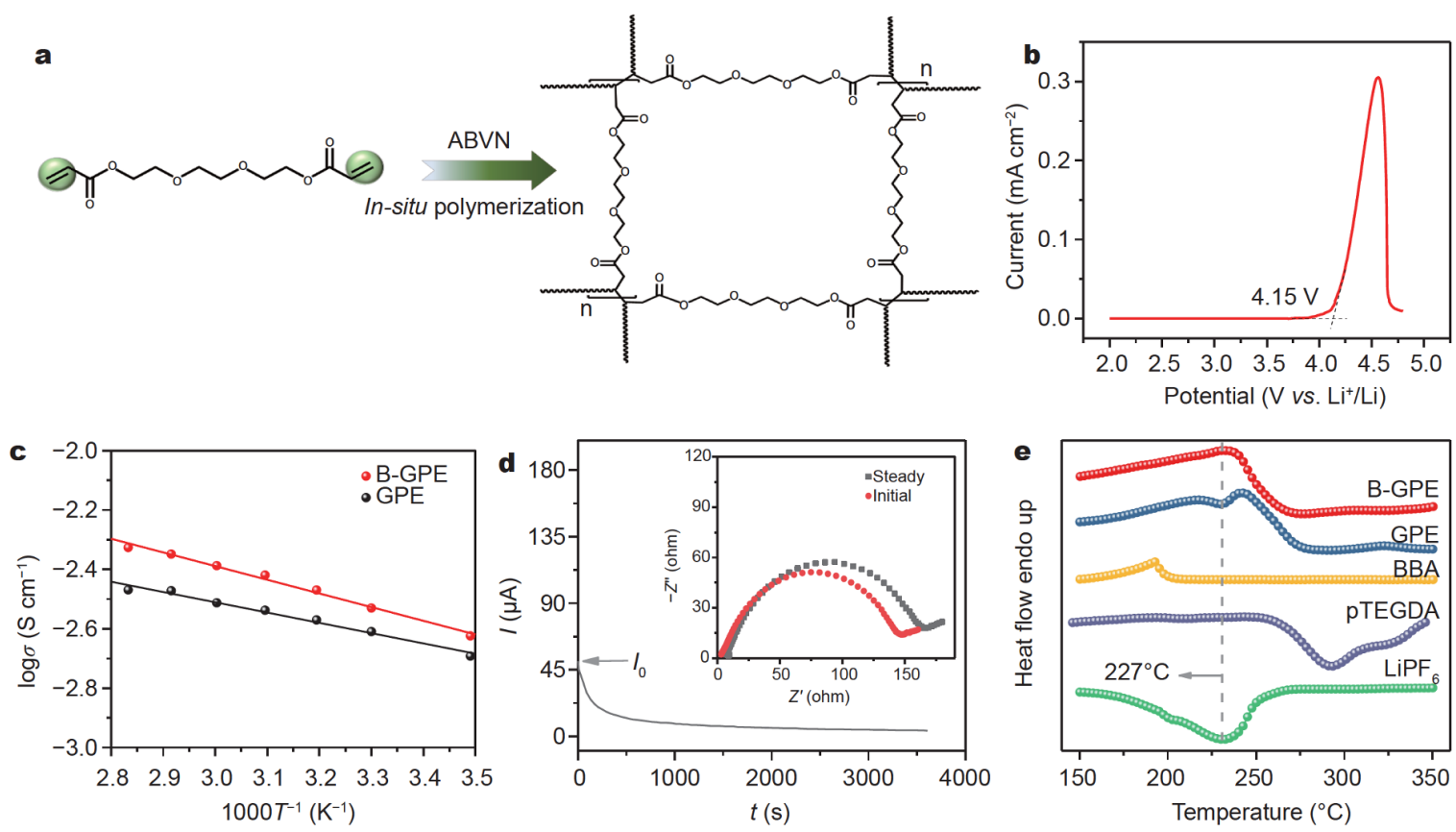

Figure 2 (a) The polymerization reaction of TEGDA with ABVN initiator; (b) LSV of B-GPE; (c) the ionic conductivities of B-GPE and GPE at different temperatures; (d) current variation with the polarization of a Li|B-GPE|Li symmetric cell with an applied potential of $30 \mathrm{mV}$ and EIS before and after polarization; (e) DSC of B-GPE, GPE, pure BBA, pTEGDA and LiPF. 


\section{GPE (Fig. S2).}

Alternative current impedance techniques were used to assess the ion-conducting properties of electrolytes [14]. The ionic conductivities of the B-GPE and GPE at $30-80^{\circ} \mathrm{C}$ are shown in Fig. $2 \mathrm{c}$. In the temperature range of $30-80^{\circ} \mathrm{C}$, the ionic conductivity of B-GPE $\left(2.4 \times 10^{-3} \mathrm{~S} \mathrm{~cm}^{-1}\right.$ at $\left.30^{\circ} \mathrm{C}\right)$ is slightly higher than that of GPE $\left(2.1 \times 10^{-3} \mathrm{~S} \mathrm{~cm}^{-1}\right.$ at $\left.30^{\circ} \mathrm{C}\right)$, which is also comparable to that of typical LEs [11]. The boron moieties in B-GPE can be regarded as Lewis acid and complex with $\mathrm{PF}_{6}{ }^{-}$due to the Lewis acid-base combination, which can promote the dissociation of lithium salts and increase the $\mathrm{Li}^{+}$ concentration. As a result, the conductivity of $\mathrm{Li}^{+}$in the B-GPE is enhanced compared with that in GPE $[23,24]$. And the lithium transference number $\left(t_{\mathrm{Li}}{ }^{+}\right)$could also be improved due to the Lewis acidity of boron moieties $[23,25,26]$. The $t_{\mathrm{Li}}{ }^{+}$of B-GPE $(0.48)$ is far higher than that of GPE (0.33) and conventional LEs (0.3 0.4) [15], as shown in Fig. $2 \mathrm{~d}$ and Fig. S3. The improved $t_{\mathrm{Li}}{ }^{+}$for BGPE is contributed by the restraining movement of $\mathrm{PF}_{6}{ }^{-}$ after combining with the boron moieties. The high $t_{\mathrm{Li}}{ }^{+}$is favorable to stabilize the deposition current of $\mathrm{Li}^{+}$and retard the dendrite growth at the surface of $\mathrm{Li}$ metal anode [27].

In conventional electrolytes, undissociated $\mathrm{LiPF}_{6}$ is easily decomposed into $\mathrm{LiF}$ and $\mathrm{PF}_{5}$ at room temperature and the latter would induce side reactions due to its high reactivity, causing the degradation of battery performance (Equations (S1-S5)) [28]. After dissociation, the chemical stability of $\mathrm{PF}_{6}^{-}$could be enhanced by the combination of BBA [29], confirmed by differential scanning calorimetry (DSC) (Fig. 2e). For the green curve, there is an exothermic peak at about $227^{\circ} \mathrm{C}$, corresponding to the decomposition of $\mathrm{LiPF}_{6}$ [29]. The exothermic peak of $\mathrm{LiPF}_{6}$ can be found in the DSC curve of GPE but not in that of B-GPE, illustrating that the decomposition of $\mathrm{LiPF}_{6}$ is restrained by BBA because of the Lewis acid-base combination between boric center and $\mathrm{PF}_{6}{ }^{-}[23,28,30]$. As a result, the cycling performance of batteries with B-GPE can be improved.

In view of the above results and analyses, B-GPE is expected to demonstrate an ultra-long cycle-life performance if used as the electrolyte for LMBs. Symmetric Lill Li cells with B-GPE, GPE, pristine LE and that with BBA additive (B-LE) were first assembled to investigate and compare their cycling performances. Note the cells based on B-LE have just a little better performance than that based on LE (Fig. S4), so further comparison of such batteries based on B-LE will not be further discussed. All $\mathrm{Li}|| \mathrm{Li}$ cells were charged and discharged under a current density of $0.5 \mathrm{~mA} \mathrm{~cm}^{-2}$ with the area capacity of $0.5 \mathrm{~mA} \mathrm{~h} \mathrm{~cm}^{-2}$. As shown in Fig. 3a, the Li|B-GPE|Li cell
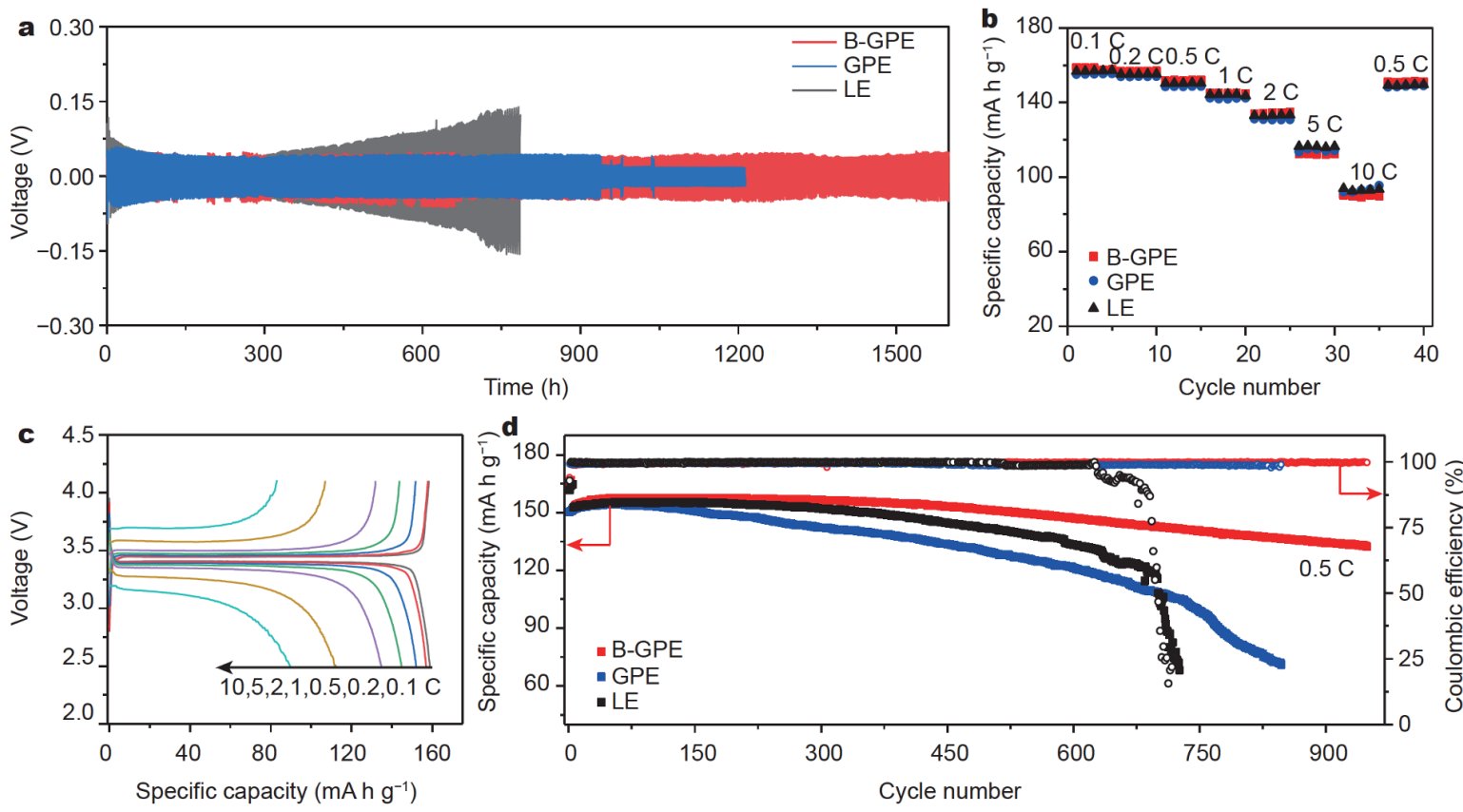

Figure 3 (a) Polarization test by using Li||Li symmetric cells with different electrolytes under a current density of $0.5 \mathrm{~mA} \mathrm{~cm}{ }^{-2}$ for the area capacity of $0.5 \mathrm{~mA} \mathrm{~h} \mathrm{~cm}^{-2}$; (b) rate capability of $\mathrm{LiFePO}_{4}|\mathrm{~B}-\mathrm{GPE}| \mathrm{Li}, \mathrm{LiFePO}_{4}|\mathrm{GPE}| \mathrm{Li}$ and $\mathrm{LiFePO}_{4}|\mathrm{LE}| \mathrm{Li}$ batteries, respectively; (c) rate capability of $\mathrm{LiFePO} \mathrm{O}_{4} \mid \mathrm{B}-$ GPE|Li batteries; (d) cycling performance of $\mathrm{Li}|| \mathrm{LiFePO}_{4}$ batteries with different electrolytes at $0.5 \mathrm{C}$ at $30^{\circ} \mathrm{C}$. 
reveals a steady overpotential around $40 \mathrm{mV}$ during the deposition and dissolution processes of $\mathrm{Li}$ which lasts more than $1600 \mathrm{~h}$. As comparison, the Li|LE|Li cell shows a rapidly growing overpotential after $400 \mathrm{~h}$, and the $\mathrm{Li}$ GPE|Li cell without the BBA additive displays enhanced cycle stability but still fails after $920 \mathrm{~h}$ due to dendriteinduced short circuits.

To further estimate the electrochemical performance of B-GPE, LMBs of $\mathrm{LiFePO}_{4}|\mathrm{~B}-\mathrm{GPE}| \mathrm{Li}, \mathrm{LiFePO}_{4}|\mathrm{GPE}| \mathrm{Li}$ and $\mathrm{LiFePO}_{4}|\mathrm{LE}| \mathrm{Li}$ were assembled and further compared. Fig. $3 \mathrm{~b}$ and Figs $\mathrm{S} 5$, S6 show that the batteries of $\mathrm{LiFePO}_{4} \mid$ B-GPE $\left|\mathrm{Li}, \quad \mathrm{LiFePO}_{4}\right| \mathrm{GPE} \mid \mathrm{Li}$ and $\mathrm{LiFePO}_{4}|\mathrm{LE}| \mathrm{Li}$ display almost similar rate performance. The charge-discharge curves of $\mathrm{LiFePO}_{4}|\mathrm{~B}-\mathrm{GPE}| \mathrm{Li}$ are displayed in Fig. 3c, which deliver reversible capacities of 157.6, 157.0, 152.1, $144.8,134.8,112.4$ and $89.7 \mathrm{~mA} \mathrm{~h} \mathrm{~g}^{-1}$ at $0.1,0.2,0.5,1,2$, 5 and $10 \mathrm{C}$, respectively. The acceptable rate performances of the batteries using B-GPE are attributed to the high ionic conductivity and the good electrochemical interfacial stability between B-GPE and the Li metal anode [14].

The cycling performances of these batteries are presented in Fig. 3d. The $\mathrm{LiFePO}_{4}|\mathrm{~B}-\mathrm{GPE}| \mathrm{Li}$ battery delivers an ultra-long cycle life with a discharge capacity of $151 \mathrm{~mA} \mathrm{~h} \mathrm{~g}^{-1}$ at the first cycle and a capacity retention of $87.7 \%$ after 950 cycles at $0.5 \mathrm{C}$. The Coulombic efficiency (CE) is higher than $99.3 \%$ at all cycle process. While the $\mathrm{LiFePO}_{4}|\mathrm{GPE}| \mathrm{Li}$ battery shows capacity retention of $70.7 \%$ after 700 cycles, and the $\mathrm{LiFePO}_{4}|\mathrm{LE}| \mathrm{Li}$ battery apparently fails to work due to a short circuit at the 690th cycle. Moreover, when the current density increases to $5 \mathrm{C}$ (Fig. S7), the $\mathrm{LiFePO}_{4}|\mathrm{~B}-\mathrm{GPE}| \mathrm{Li}$ battery still shows great cycling stability for over 350 cycles with a quite stable CE than that of other two batteries. Moreover, when the mass load of $\mathrm{LiFePO}_{4}$ is up to $12 \mathrm{mg} \mathrm{cm}^{-2}$, the $\mathrm{LiFePO}_{4}|\mathrm{~B}-\mathrm{GPE}| \mathrm{Li}$ battery still reveals stable cycle performance (Fig. S8). To the best of our knowledge, the cycle performance of $\mathrm{LiFePO}_{4}|\mathrm{~B}-\mathrm{GPE}| \mathrm{Li}$ battery in this work is the best among similar reported studies and also far superior to the performance of some reported solid electrolytes for LMBs (Table S1).

Scanning electron microscopy (SEM) analysis was performed to observe the surface morphology of the lithium metal anodes with different electrolytes after 100 cycles at 0.5 C. As shown in Fig. $4 a$ and Figs S9, S10, a smooth morphology can be achieved by using the B-GPE. In contrast, some dendrites could be easily observed at the lithium metal anode with GPE (Fig. S11), and massive sharp dendrites are at the lithium metal anode with LE (Fig. 4b).
The electrochemical impedance spectroscopy (EIS) results are shown in Fig. 4c, d and Figs S12, S13 to explore the change of resistance. The intersection of the diagram with the axis refers to a bulk resistance $\left(R_{\mathrm{b}}\right)$, reflecting the resistance of electrolyte. The depressed semicircle at high frequency can be attributed to the interface resistance $\left(R_{\mathrm{i}}\right)$. The slope line in the low frequency region corresponds to the $\mathrm{Li}^{+}$diffusion impedance. In the first few cycles, the internal resistance of $\mathrm{LiFePO}_{4}|\mathrm{~B}-\mathrm{GPE}| \mathrm{Li}$ keeps decreasing because of the improved interface between the electrolyte and electrodes during charging and discharging [31]. Based on the average values for the three cells, with the increase of the cycle numbers, the change slopes of internal resistance of the three batteries are different, $0.08 \Omega$ per cycle of $\mathrm{LiFePO}_{4}|\mathrm{~B}-\mathrm{GPE}| \mathrm{Li}$ battery, $0.14 \Omega$ per cycle of $\mathrm{LiFePO}_{4}|\mathrm{GPE}| \mathrm{Li}$ battery and $0.37 \Omega$ per cycle of $\mathrm{LiFePO}_{4}|\mathrm{LE}| \mathrm{Li}$ battery (Fig. $4 \mathrm{~d}$ ). It is apparent that the $\mathrm{LiFePO}_{4}|\mathrm{~B}-\mathrm{GPE}| \mathrm{Li}$ displays an internal resistance with negligible change after 150 cycles, while that of $\mathrm{LiFePO}_{4} \mid$ LE|Li increases drastically. The EIS results are consistent with the SEM results, indicating that the growth of dendrite is the origin of the increased internal resistance and the inferior cycling performance of $\mathrm{LiFePO}_{4}|\mathrm{GPE}| \mathrm{Li}$ and $\mathrm{LiFePO}_{4}|\mathrm{LE}| \mathrm{Li}$. Moreover, X-ray diffraction (XRD) spectra are shown in the Fig. 5a and Fig. S14, and there is no peak of $\mathrm{LiOH}$ found at the surface of $\mathrm{Li}$ anode using $\mathrm{B}$ GPE electrolyte. Since $\mathrm{LiOH}$ is the product of side reactions between $\mathrm{Li}$ and organic electrolytes, it can be concluded that the B-GPE is beneficial for protecting the $\mathrm{Li}$ metal anode by constructing a stable SEI film [16].

Furthermore, X-ray photoelectron spectroscopy (XPS) (Fig. S15) and FTIR spectra were used to characterize the composition of the SEI films obtained from the LMBs after 100 cycles at $0.5 \mathrm{C}$ using B-GPE, GPE and LE electrolytes. The extra $\mathrm{B}-\mathrm{O}$ peaks can be observed in the $B$ 1s spectrum (Fig. 5b), suggesting that BBA additive could contribute to the construction of the SEI film [24]. This result also can be confirmed by FTIR spectra (Fig. 5c). In the reflection FTIR spectrum of the SEI in batteries using B-GPE, some new peaks appear at 1060 and $1384 \mathrm{~cm}^{-1}$ [24,32], which are assigned to the $\mathrm{B}-\mathrm{O}$ vibrations, same as that from the control experiment based on pure BBA. The XPS results confirm that the BBA additive in B-GPE could play an important role in forming a boron-based SEI film, which agrees with the XRD results. Therefore, the in-situ polymerization ensures the good interfacial compatibility between the lithium anode and electrolyte. And the B-GPE could promote the dissociation of $\mathrm{LiPF}_{6}$, reducing the side reactions in gel electrolyte. Simultaneously it constructs a 
a
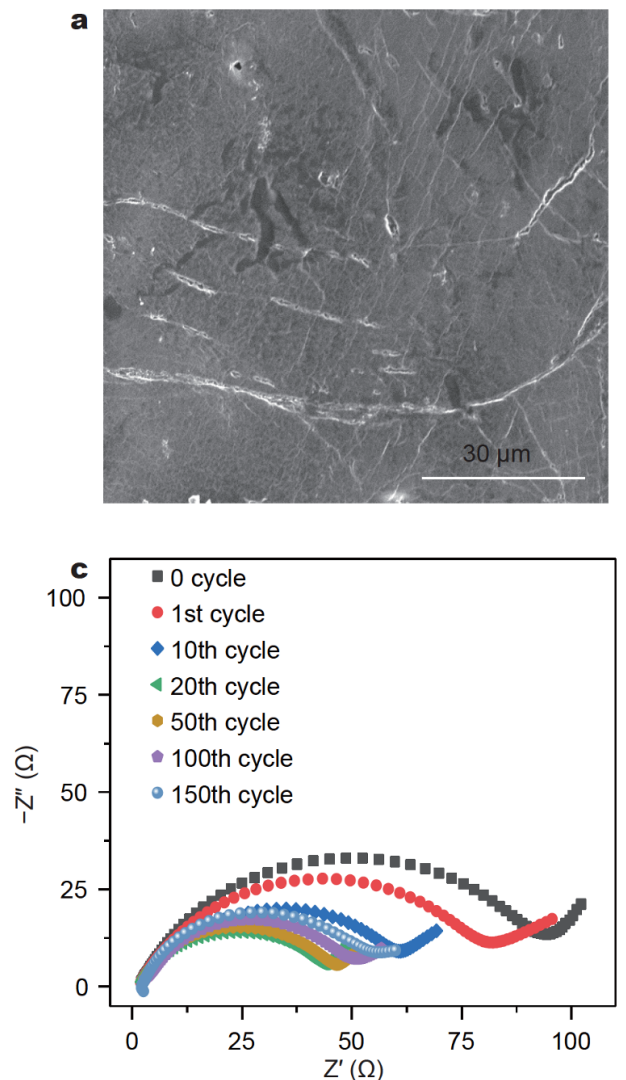

b
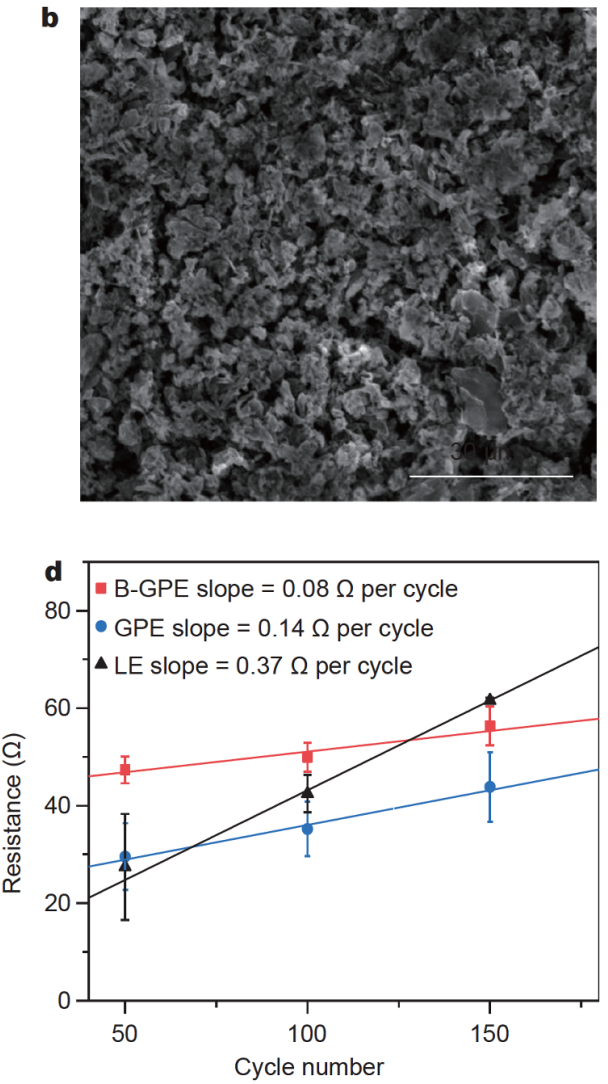

Figure $4 \mathrm{SEM}$ morphology of the $\mathrm{Li}$ anode surface obtained from $\mathrm{Li} \mid \mathrm{LiFePO}_{4}$ battery using (a) B-GPE and (b) LE after 100 cycles at $0.5 \mathrm{C}$. (c) Impedance response with cycling evolution of the $\mathrm{LiFePO}_{4}|\mathrm{~B}-\mathrm{GPE}| \mathrm{Li}$ at $0.5 \mathrm{C}, 30^{\circ} \mathrm{C}$; (d) the resistances evolution of $\mathrm{Li} \mid \mathrm{LiFePO} \mathrm{B}_{4}$ batteries using different electrolytes after 50 cycles at $0.5 \mathrm{C}, 30^{\circ} \mathrm{C}$.
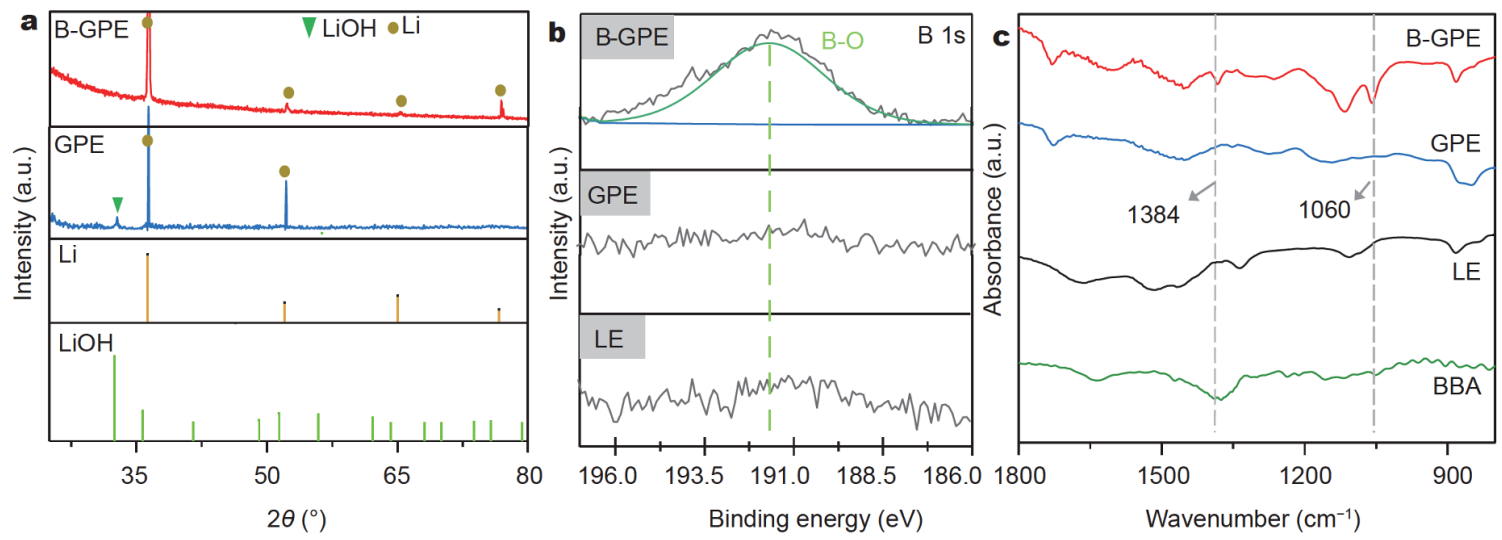

Figure 5 (a) XRD patterns; (b) XPS spectra and c) FTIR absorbance spectra of the SEI film on the Li anodes surface based on different electrolytes.

boron-based SEI film, which is favorable for the inhibition of dendrites and ultra-long cycling.

Taking the dual effects of in-situ polymerization in LE and boric acid additive, a novel gel-like electrolyte B-GPE was prepared and demonstrated an ultra-long cycle-life performance for LMBs. The in-situ polymerization ensures the good interface contact between the electrodes and electrolytes. Furthermore, the additive BBA enhances the stability of $\mathrm{LiPF}_{6}$ in the gel electrolyte, reducing the side reactions with electrolyte solvents, and it could 
contribute to the construction of the SEI film, effectively preventing Li dendrite growth. Together with the above features, the LMB using such a gel electrolyte B-GPE possesses ultra-long cycle-life performance, $87.7 \%$ capacity retention after cycling for 950 cycles, much better than that of the batteries based on conventional LE and the gel electrolyte without the BBA additive. Thus, our approach with a dual effect from both in-situ electrolyte polymerization and the BBA additive could make it one promising method for the next generation LMBs with both high ionic conductivity and ultra-long cycle-life performance.

Received 2 March 2020; accepted 15 April 2020; published online 15 June 2020

1 Li S, Jiang M, Xie Y, et al. Developing high-performance lithium metal anode in liquid electrolytes: challenges and progress. Adv Mater, 2018, 30: 1706375

2 Zhou Y, Han Y, Zhang H, et al. A carbon cloth-based lithium composite anode for high-performance lithium metal batteries. Energy Storage Mater, 2018, 14: 222-229

3 Zhou Y, Zhao K, Han Y, et al. A nitrogen-doped-carbon/ZnO modified $\mathrm{Cu}$ foam current collector for high-performance Li metal batteries. J Mater Chem A, 2019, 7: 5712-5718

4 Yang C, Liu B, Jiang F, et al. Garnet/polymer hybrid ion-conducting protective layer for stable lithium metal anode. Nano Res, 2017, 10: 4256-4265

5 Li N, Wei W, Xie K, et al. Suppressing dendritic lithium formation using porous media in lithium metal-based batteries. Nano Lett, 2018, 18: 2067-2073

6 Yang C, Zhang L, Liu B, et al. Continuous plating/stripping behavior of solid-state lithium metal anode in a 3D ion-conductive framework. Proc Natl Acad Sci USA, 2018, 115: 3770-3775

7 Kraft MA, Ohno S, Zinkevich $\mathrm{T}$, et al. Inducing high ionic conductivity in the lithium superionic argyrodites $\mathrm{Li}_{6+x} \mathrm{P}_{1-x} \mathrm{Ge}_{x} \mathrm{~S}_{5} \mathrm{I}$ for all-solid-state batteries. J Am Chem Soc, 2018, 140: 16330-16339

8 Liu L, Lyu J, Mo J, et al. Flexible, high-voltage, ion-conducting composite membranes with $3 \mathrm{D}$ aramid nanofiber frameworks for stable all-solid-state lithium metal batteries. Sci China Mater, 2020, 63: 703-718

9 Chai J, Liu Z, Ma J, et al. In situ generation of poly (vinylene carbonate) based solid electrolyte with interfacial stability for Li$\mathrm{CoO}_{2}$ lithium batteries. Adv Sci, 2017, 4: 1600377

10 Cheng X, Pan J, Zhao Y, et al. Gel polymer electrolytes for electrochemical energy storage. Adv Energy Mater, 2018, 8: 1702184

11 Liu M, Zhou D, He YB, et al. Novel gel polymer electrolyte for high-performance lithium-sulfur batteries. Nano Energy, 2016, 22: 278-289

12 Wang $\mathrm{K}$, Zhang X, Sun X, et al. Conducting polymer hydrogel materials for high-performance flexible solid-state supercapacitors. Sci China Mater, 2016, 59: 412-420

13 Yu D, Li X, Xu J. Safety regulation of gel electrolytes in electrochemical energy storage devices. Sci China Mater, 2019, 62: 15561573

$14 \mathrm{Lu} \mathrm{Q}, \mathrm{He} \mathrm{YB}, \mathrm{Yu} \mathrm{Q}$, et al. Dendrite-free, high-rate, long-life lithium metal batteries with a 3D cross-linked network polymer electrolyte.
Adv Mater, 2017, 29: 1604460

15 Fan W, Li NW, Zhang X, et al. A dual-salt gel polymer electrolyte with $3 \mathrm{D}$ cross-linked polymer network for dendrite-free lithium metal batteries. Adv Sci, 2018, 5: 1800559

16 Huang $\mathrm{Z}$, Ren J, Zhang W, et al. Protecting the Li-metal anode in a $\mathrm{Li}-\mathrm{O}_{2}$ battery by using boric acid as an SEI-forming additive. Adv Mater, 2018, 30: 1803270

17 Fan $\mathrm{H}, \mathrm{Li} \mathrm{H}$, Fan LZ, et al. Preparation and electrochemical properties of gel polymer electrolytes using triethylene glycol diacetate-2-propenoic acid butyl ester copolymer for high energy density lithium-ion batteries. J Power Sources, 2014, 249: 392-396

18 Liu FQ, Wang WP, Yin YX, et al. Upgrading traditional liquid electrolyte via in situ gelation for future lithium metal batteries. Sci Adv, 2018, 4: eaat5383

19 Niu C, Zhang M, Chen G, et al. An effectively inhibiting lithium dendrite growth in-situ-polymerized gel polymer electrolyte. Electrochim Acta, 2018, 283: 349-356

20 Bok T, Cho SJ, Choi S, et al. An effective coupling of nanostructured $\mathrm{Si}$ and gel polymer electrolytes for high-performance lithium-ion battery anodes. RSC Adv, 2016, 6: 6960-6966

21 Tan R, Gao R, Zhao Y, et al. Novel organic-inorganic hybrid electrolyte to enable $\mathrm{LiFePO}_{4}$ quasi-solid-state $\mathrm{Li}$-ion batteries performed highly around room temperature. ACS Appl Mater Interfaces, 2016, 8: 31273-31280

22 Zhang SS, Angell CA. A novel electrolyte solvent for rechargeable lithium and lithium-ion batteries. J Electrochem Soc, 1996, 143: 4047

23 Cai Z, Liu Y, Zhao J, et al. Tris(trimethylsilyl) borate as electrolyte additive to improve performance of lithium-ion batteries. J Power Sources, 2012, 202: 341-346

24 Liu Q, Yang G, Liu S, et al. Trimethyl borate as film-forming electrolyte additive to improve high-voltage performances. ACS Appl Mater Interfaces, 2019, 11: 17435-17443

25 Matsumi N, Sugai K, Miyake M, et al. Polymerized ionic liquids via hydroboration polymerization as single ion conductive polymer electrolytes. Macromolecules, 2006, 39: 6924-6927

26 Quartarone E, Mustarelli P. Electrolytes for solid-state lithium rechargeable batteries: recent advances and perspectives. Chem Soc Rev, 2011, 40: 2525-2540

27 Chen L, Li W, Fan L-, et al. Intercalated electrolyte with high transference number for dendrite-free solid-state lithium batteries. Adv Funct Mater, 2019, 29: 1901047

28 Han J-, Kim K, Lee Y, et al. Scavenging materials to stabilize $\mathrm{LiPF}_{6}$ containing carbonate-based electrolytes for Li-ion batteries. Adv Mater, 2019, 31: 1804822

29 Wang Q, Jiang L, Yu Y, et al. Progress of enhancing the safety of lithium ion battery from the electrolyte aspect. Nano Energy, 2019, 55: $93-114$

30 Aravindan V, Gnanaraj J, Madhavi S, et al. Lithium-ion conducting electrolyte salts for lithium batteries. Chem Eur J, 2011, 17: 14326-14346

31 Lin Z, Guo X, Yu H. Amorphous modified silyl-terminated 3D polymer electrolyte for high-performance lithium metal battery. Nano Energy, 2017, 41: 646-653

32 Zhu YS, Gao XW, Wang XJ, et al. A single-ion polymer electrolyte based on boronate for lithium ion batteries. Electrochem Commun, 2012, 22: 29-32

Acknowledgements The authors gratefully acknowledge the financial support from the Ministry of Science and Technology of China 
(2016YFA0200200), the National Natural Science Foundation of China (21421001 and 51633002), Tianjin city (16ZXCLGX00100) and 111 Project (B12015)

Author contributions Han Y, Chen Y and Zhou Y designed the project; Han Y fabricated the electrolyte and assembled the cells. Zhu J and Sun $Z$ finished the XRD characterization; Han Y wrote the paper with support from Chen Y, Zhang H, Sun Z, Ma Y and Li C. All authors contributed to the general discussion.

Conflict of interest The authors declare no conflict of interest.

Supplementary information Experimental details and supporting data are available in the online version of the paper.

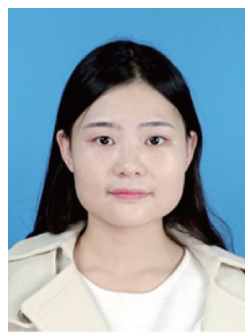

Yu Han is currently a graduate student at Nankai University under the direction of Prof. Yongsheng Chen. She obtained her BSc degree from Lanzhou University in 2017. Her main research interests are focused on gel electrolyte and the related applications in energy storage.

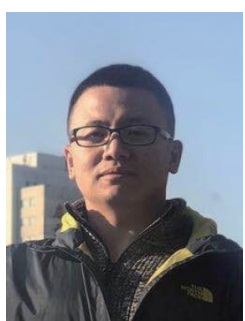

Hongtao Zhang received his $\mathrm{PhD}$ degree from the Institute of Chemistry, Chinese Academy of Sciences in 2012. He joined Prof. Yongsheng Chen's group at Nankai University in 2014. Thereafter, he became an associate professor. His current research interests mainly focus on the synthesis and characterization of organic and polymer functional materials and their application in energy conversion and storage devices.

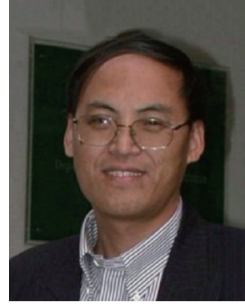

Yongsheng Chen graduated from the University of Victoria with a $\mathrm{PhD}$ degree in chemistry in 1997 and then joined the University of Kentucky and the University of California at Los Angeles for postdoctoral studies from 1997 to 1999. From 2003, he has been a Chair Professor at Nankai University. His main research interests include: i) carbon-based nanomaterials, including carbon nanotubes and graphene; ii) organic and polymeric functional materials, and iii) energy devices including organic photovoltaics and supercapacitors.

\section{利用原位聚合/硼酸双重作用的凝胶电解质获得 超长寿命锂金属电池}

韩宇, 周颖, 朱洁, 孙振贺, 徐灵群, 李晨曦, 马延凤, 张洪涛", 陈永胜

摘要 锂金属电池具有能量密度高的优点, 有望成为下一代可充电 电池. 然而, 其液态电解液泄露的风险及锂枝晶生长造成的短路等 问题阻碍了其应用. 使用凝胶电解质被认为是提高锂金属电池安 全性的有效方法, 但是因锂枝晶生长导致循环寿命差的问题仍未 有效解决. 本文设计了一种结合原位聚合和硼酸添加剂双重效果 的凝胶电解质(B-GPE), 并组装了锂金属电池进行测试. 其中, 原位 聚合的方法使得凝胶电解质与电极界面接触良好, 嗍酸添加剂一 方面可以增强锂盐的稳定性, 抑制副反应发生; 另一方面可以形成 稳固的SEI膜, 抑制锂枝晶的生长. 以上双重作用使得这种凝胶电解 质应用于锂金属电池可以获得超长循环寿命, 在 $0.5 \mathrm{C}$ 的倍率下循 环 950 圈仍有 $87.7 \%$ 的容量保持率, 是目前类似的凝胶电解质、液 态电解液和固态电解质应用中循环寿命最出色的. 该结果证明结 合原位聚合和硼酸添加剂双重效果是制备高性能凝胶电解质的简 单且有效的策略, 并进一步为锂金属电池的广泛应用提供了有价 值的方法. 